\title{
The Use of YouTube to Improve Students' Acuity and Analytic Skills in Discussion of Issues in Music Performance
}

\author{
Heather Monkhouse, Anne-Marie Forbes \\ University of Tasmania, Australia
}

\begin{abstract}
The emergence of YouTube as a public and easily accessible resource for musical performances provides both opportunities and challenges for tertiary level music teaching. The simultaneous combination of visual and aural recognition greatly aids the understanding of music performance practice issues: listening and scrutiny of video footage of both historical and recent performances is an important research activity for developing understanding of past and current performance practices. Such learning enables the skill development and stylistic awareness to underpin more authentic or aesthetically pleasing individual musical interpretation and performance.

The authors conducted a study in 2012 to evaluate the use of YouTube footage in classroom settings to initiate discussion of performance practices and raise students' awareness of the effect of the individual persona on a given interpretation. The study found that students developed a more nuanced understanding of what was needed, visually and aurally, to create stylish and professionally credible performances as well as gaining greater awareness and understanding of criteria that can be used to assess the performance of others. A follow up study in 2014 evaluated tertiary music performance students' subsequent use of YouTube outside the classroom environment. The data strongly suggests that the earlier use of YouTube as a teaching tool in the curriculum and the development of critical awareness and judgment in that forum has contributed to this cohort's willingness to engage with this audio-visual resource for personal learning and that they exhibit a high degree of critical judgment in their viewing and use of the resource.
\end{abstract}

\section{Introduction}

In 2012, YouTube You Learn, a pilot study, was undertaken at the Conservatorium of Music, University of Tasmania, to explore the value of using YouTube footage in classroom settings to initiate discussion on points on performance practice and to raise students' awareness of the effect of the individual persona on interpretation and presentation. The study was timely, as the variety of materials posted on YouTube in the visual and performing arts was ever increasing, and anecdotal evidence from the students indicated that many were accessing these resources regularly as models for their own instrumental practice. Given this usage, it was deemed important that there needed to be processes embedded within the curriculum for developing the students' critical facilities to enable them to choose wisely when accessing performance models from online resources. Performance staff, at the time, also reported concerns regarding the ability of students to engage effectively in discussions about performance issues. Some students, particularly the first year students, found it daunting to analyse and then share their thoughts about performances of their fellow students, and while some of the hesitation was in part due to both their newness to the institution and the unfamiliarity of the task, nevertheless staff noted that many students struggled to access the vocabulary necessary to explore specific performance issues and musical concepts successfully. As a result, the authors successfully sought institutional teaching development grant funding that facilitated embedding assessment tasks using YouTube materials into two units of music history study in the Conservatorium's Bachelor of Music degree. YouTube You Learn, also aimed, to enhance student awareness of the performance-research nexus thus situating the study in music history units was a strategy employed for multiple reasons. Firstly this encouraged broadening of research skills to include online audiovisual resources, secondly it raised awareness of the usefulness of good research skills when sourcing performance materials and thirdly it provided students with opportunities to use this knowledge to interrogate issues of performance practice. Finally, the process would help students develop the communication skills required for objective, detailed and insightful analysis and more objective critique of music performance. The success of the pilot study led to the ongoing use of assessment tasks in music history units that specifically require students to compare two performances of the same musical work sourced from YouTube. Three years after the initial pilot study, a follow up study was conducted in December 2014 with performance students at the Conservatorium of Music, University of Tasmania to discover the extent to which they employed critical thinking processes in their usage of online music resources outside the classroom environment. 


\section{The accessibility of online resources and the prevalence of YouTube}

In 2011 The Horizon Report ranked six emerging technologies or practices likely to enter mainstream use within the next five years, and listed as number one, "the abundance of resources and relationships made easily accessible via the internet," observing that these would be "... increasingly challenging us to revisit out roles as educators in sense-making, coaching, and credentialing" [3]. The report continued: With personal access to the Internet from mobile devices on the rise, the growing set of resources available as open content, and a variety of reference and textbooks available electronically, students' easy and pervasive access to information outside of formal campus resources continues to encourage educators to take a careful look at the ways we can best serve learners [3].

Four years later, in 2015, The Horizon Report recognised "Bring Your Own Device (BYOD)" as an important development in educational technology for Higher Education, estimating a time to adoption horizon as one year or less [4]. It noted: The link between the use of personal devices and increases in productivity gets stronger each passing year as more organizations adopt BYOD policies. The integration of personal smartphones, tablets, and PCs into the workflow supports an on-the-go mentality, changing the nature of work and learning activities so that they can happen anywhere, at anytime [4]. YouTube, launched in November 2005, has proven to be particularly popular to the extent that in 2013 Business Insider Australia described YouTube as "the world's most popular online video site, with users watching 4 billion hours worth of video each month and uploading 72 hours worth of video every minute" [2]. Not surprisingly, the potential of YouTube as a repository for educational resources has received significant scholarly attention, particularly in the growth of educational videos and video-sharing webpages across a number of disciplines [8]. As a research tool, however, the potential of YouTube, and other online video sharing sites, has received less scrutiny. De Witt et al explored the potential of YouTube in the teaching of the performing arts, after positing, "learners remember and understand better when they see, hear and do" [1].

Their findings included a recommendation for further studies to determine the effectiveness of using YouTube to other subject areas [1]. It is apparent, that for music performance students, the sheer wealth of material easily accessible through the internet now makes it possible for them to "experience the diverse world (and its array of musics) in ways that were inconceivable to previous generations" [7].
For music students YouTube footage also enables direct access to a vast array of performance techniques, interpretative decisions and visual cues that can be replayed and reviewed at will, thus affording a learning tool of great potential: it may be used as "a tool to inform and display and as a forum for critical analysis and commentary" [5]. Challenges, however, are posed by the richness of the environment, ease of access and the highly variable quality of the performances uploaded. Students need to gain awareness of how to choose wisely and the tertiary music educator must help these emerging practising artists to develop a critical and contextual filter so these materials can be used effectively and learning optimised.

\section{2012: YouTube You Learn project}

The purpose of the 2012 project was to use YouTube footage to help students gain higher levels of awareness of performance practice issues, to improve their analytic skills in identifying the criteria of both good and bad exemplars, and to develop a greater sensitivity towards what is needed visually and aurally, including demeanour and gesture, in order to create a stylish and professionally credible performance. A critical feature of the project was the development of assignments requiring students to find YouTube examples, affording students a sense of ownership of the materials and better understanding of how research materials may be used to support and inform opinion. Class discussions developed the students' ability to use sight and sound (senses used daily in individual practice) critically to analyse other performers' work: the experience of using practical analytic skills in the classroom as a methodology to pursue research, helped students to understand how knowledge of history may inform practice.

Two music history units offered at the Conservatorium in semester 2, 2012, one a first year unit, the second a third year capstone unit were used in the trial. To engage the students in class discussions about performance practice, a database with three to five examples sourced from YouTube for each of the works on the listening list for the first year unit was created. The database included the URL for each YouTube example, the timing, the artists, and a broad rating of the level of the performer's professional status (amateur, semiprofessional or professional). The database was uploaded into the unit's intranet site and students were able to access and reflect on the examples as well as offer suggestions of new examples they found to be added to the works in the database.

As part of the project two assignment tasks were developed, the first was used for both cohorts and the second only for the third year students. The first assignment required students to find two YouTube 
clips of a specific work/movement of a work. The students then had to create a short powerpoint presentation (as a guideline the first year were advised to have no more than 6 slides, no fewer than 3 ; there was no limit for the third years but most created between 5 and 8 slides), setting out highlights of the individual performances and including points of similarity and difference in interpretation or performance practice. The third year students were then required to give the oral presentation to the class and also asked to reflect on the possible reasons behind the performers' interpretative decisions. All examples were collated and entered into a database, uploaded to the unit's intranet site, and made available to the students. The third year students, in their second assessment task, were asked to reflect upon their personal preparation of a work they were planning to perform in their end of year recital. Students were encouraged to source YouTube examples as well as CD and any DVD resources for comparative purposes and to discuss their reasons for the interpretive decisions made during their own rehearsal processes.

The findings from this project revealed that the first assessment task established a methodology that allowed the students to develop the skills and confidence to assess and analyse performance practice more critically. Asking students to compare two performances of the same work sourced from YouTube had the additional advantage of lending a higher degree of objectivity to the tenor of class discussions, as the performers were not colleagues. Students' comments concentrated, at first, on highlighting similarities and differences in the details of each performance but over time, the focus moved more quickly to discussion on reasons for particular interpretative decisions, and then why one version might be preferred.

Towards the end of the pilot the ability of the students to engage in class discussions was examined. Both lecturers reported that discussions towards the end of the semester indicated a far greater awareness by the students of the impact of stage presentation, audience expectations, and the possible aesthetic vision in effective performances. The lecturer of the third year class also reported that these students seemed to have found the methodology helpful when reflecting on their own practice. Additionally, the first year students were asked, during a class discussion, what effect the powerpoint presentation had had on their studies. Their comments recognised the impact of comparison for they acknowledged that they had found learning the listening list far easier after the powerpoint assignment: recognition of the pieces quickly became assumed knowledge, as the focus of their listening shifted to consideration of how the music was being projected and presented.
The results of the pilot study underscored the value of using YouTube materials in the classroom to encourage student engagement in critical evaluation of music performance issues. Upon its conclusion it was decided to embed the assessment tasks developed as part of the study into all the first year music history units as well as the third year capstone unit.

\section{Follow up study: 2014}

In November 2014 a small follow up study was undertaken in which music performance students at the Conservatorium of Music, University of Tasmania were contacted through email and invited to participate in a survey, developed and delivered through Survey Monkey. This survey was designed to explore the manner in which they engaged with and used audio and digital materials, particularly YouTube, outside the classroom environment. Participation was voluntary and anonymous, with the survey running for three weeks, commencing in the second week of the end of year examination period and ending one week after examinations concluded. A total of 102 students were contacted and 40 students chose to participate, representing a $39 \%$ response rate. The survey remained open to the students for three weeks. Of the respondents 32 (79\%) were undergraduate and $8(20 \%)$ were postgraduate students. $19 \quad(47 \%)$ identified themselves as classical music students and 21 (53\%) as contemporary musicians or singer-songwriters.

Although the response rate was lower than the optimum, the distribution in both categories was representative of the Conservatorium's music performance student cohorts for that year.

The survey comprised 26 questions, asking students to provide both quantitative and qualitative information. Line by line analyses were conducted on all individual responses and the Survey Monkey software was used to identify common responses as well as to tabulate the frequency of concepts. The survey asked a number of questions relating to their usage of audio and digital online resources, including, but not limited to, YouTube materials.

\subsection{Results}

The results of the survey confirmed Dickey's opinion: YouTube, was a popular resource for these students [2]. Importantly for this study, YouTube was accessed regularly to source music performance repertoire. All the students reported they viewed YouTube materials regularly, with 36 students (93\%), indicating their usage was, at the very least, more frequent since they had commenced tertiary music study (see Figure 1). 


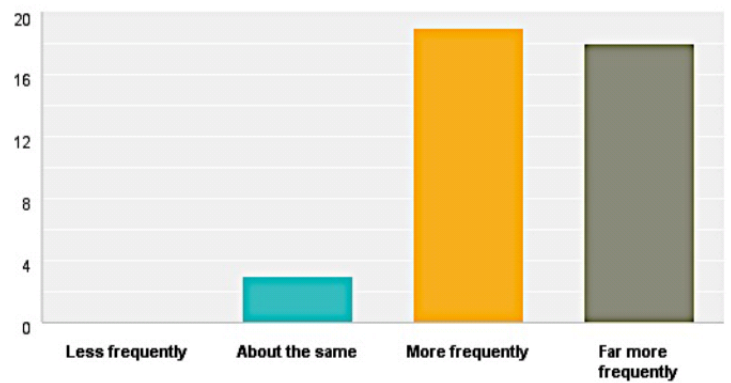

Figure 1: Student responses to the question: "How often do you use music performance YouTube materials, in comparison to your use prior to starting tertiary study?

The survey results also revealed that both online and offline resources were used: other than YouTube, iTunes, CDs and DVDs were the resources students reported as being used most regularly (Figure 2). The students also indicated music streaming, and particularly, Spotify, a subscription-based music streaming service, and live concerts as regular and useful sites to hear music that was relevant to their music performance studies.

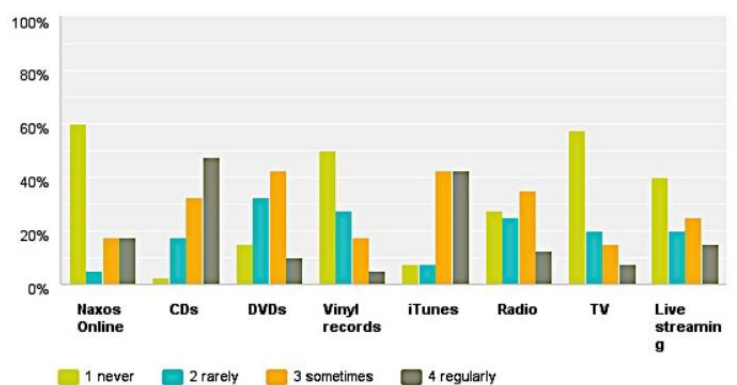

Figure 2: Student responses to the question: "What sources, other than YouTube, do use

(watch/listen) to learn music?"

The students were also asked that if they had to choose between using YouTube video or hard copy sources, which would be their preference. Their responses showed this cohort was fairly evenly divided, but $22(56 \%)$ chose YouTube predominantly for its accessibility, which supports the trend supposed by The Horizon Report in 2011. As one student wrote "I would choose YouTube videos because they're easier for me to access" (student respondent \#22) and, similarly, another commented "I love my CDs but YouTube is quite easily accessible now and if you are at home and that Brahms CD you what is in the library then it is much easier to go online to YouTube /Naxos and listen. So YouTube"(student respondent \#2). Other reasons emerged, beyond accessibility. For example, one student reported "YouTube. Often I will discover new material in the related video suggestion section" (student respondent \#5). The diversity and range of material available was an important decider for, as one student stated, "YouTube, because you can watch amateur and professional performances and get a better idea of things to avoid" (student respondent \#10). The other theme that emerged from the students' comments, was that for some students accessing YouTube was an opportunity to enhance learning: "I would prefer to use YouTube videos as I find they are generally live, unedited videos (the ones I generally watch) so more realistic from a performance practice perspective and I learn more about technique from seeing other performers perform" (student respondent \#34).

To discover the extent to which students used YouTube to support their performance studies, the students were asked three specific questions as to why they might access YouTube materials (see Table 1 ). The responses indicated that a high proportion of the students, $34(85 \%)$ used YouTube at least regularly to listen to specific pieces, and $36(90 \%)$ at least accessed YouTube regularly to listen to specific performers. The students were then asked if they learnt a new piece first without listening or watching other performances. Their responses indicated that the majority of students did access other performances to guide their learning: significantly 9 $(23 \%)$ indicated they would not start learning at all without listening or watching other performances, $17(44 \%)$ reported they did so occasionally, while for $9(23 \%)$ their process was that they regularly learnt new repertoire without listening to others, and only 4 (10\%) always learnt new repertoire without first listening or watching other performers. The responses to these questions suggest very strongly that for these students YouTube is a heavily used resource used to assist their music performance study.

Table 1. Student responses to questions "Why you might access YouTube materials"

\begin{tabular}{|l|c|c|c|c|}
\hline Answer Options & $\begin{array}{l}\text { 1 not at } \\
\text { all }\end{array}$ & $\begin{array}{l}\text { on } \\
\text { occasion }\end{array}$ & 3 regularly & $\begin{array}{l}4 \text { yes, all } \\
\text { the time }\end{array}$ \\
\hline $\begin{array}{l}\text { Do you use YouTube to listen to } \\
\text { specific pieces? }\end{array}$ & 1 & 4 & 12 & 22 \\
\hline $\begin{array}{l}\text { Do you use YouTube to } \\
\text { listen/watch specific performers? }\end{array}$ & 0 & 3 & 19 & 17 \\
\hline $\begin{array}{l}\text { When learning a new piece do you } \\
\text { learn first without } \\
\text { listening/watching other } \\
\text { performances? }\end{array}$ & 9 & 17 & 9 & 4 \\
\hline
\end{tabular}

The survey then asked the students to indicate on average how frequently they accessed music performance materials on YouTube. 19 students (49\%) reported usage from once a week to once every few days, 6 students $(15 \%)$ indicated once a week, while for 13 students (33\%) it was once every few days. Significantly half the cohort, 20 students $(51 \%)$, reported that they accessed YouTube music performance materials, on average, at least once a 
day. In their comments, however, some students indicated that their access was far more than once or even twice a day. One student found it difficult to quantify and wrote "it's practically second nature that I do not even realise I'm on YouTube again" (student respondent \# 3), while another commented he/she spent "as much time as I have spare on a daily basis. If YouTube was a religion I would go to church. Has been that way since I first discovered it" (student respondent \#2).

The students were also asked to provide information as to their process when researching specific repertoire. 34 students $(87 \%)$ reported they used YouTube to discover pieces that might become part of their recital repertoire and 37 students (95\%) indicated they listened to different versions of the pieces they planned to perform. When asked if their intention was to watch or listen to more than one performance (interpretation) of a specific piece the response was $100 \%$ affirmative. For all the students the idea of comparing performances was embedded in their practice. Furthermore, comparison of different performers was preferred: 17 students (44\%) required 2 different performers' interpretations while even more (22 students (57\%)) indicated they sourced at least three different performers' interpretations as their normal practice (see Table 2).

Table 2: Student responses to the question, "Do you regularly aim to watch/listen to more than one performance (interpretation) of a specific piece?"

\begin{tabular}{|l|r|r|}
\hline $\begin{array}{l}\text { Do you regularly aim to watch/listen to more than one performance (interpretation) } \\
\text { of a specific piece? }\end{array}$ \\
\hline Answer Options & $\begin{array}{l}\text { Response } \\
\text { Percent }\end{array}$ & $\begin{array}{l}\text { Response } \\
\text { Count }\end{array}$ \\
\hline No & $0.0 \%$ & 0 \\
\hline Rarely & $0.0 \%$ & 0 \\
\hline Yes usually 2 performances by the same performer/s & $2.6 \%$ & 1 \\
\hline Yes usually 2 performances by two different performer/s & $28.2 \%$ & 11 \\
\hline Yes usually 3 performances by the same performer/s & $2.6 \%$ & 1 \\
\hline $\begin{array}{l}\text { Yes usually 3 performances by at least two different } \\
\text { performer/s }\end{array}$ & $15.4 \%$ & 6 \\
\hline $\begin{array}{l}\text { Yes usually 3 (or more) performances by three different } \\
\text { performer/s }\end{array}$ & $56.5 \%$ & 22 \\
\hline
\end{tabular}

To gain further insights into how the students subsequently used the footage they sourced from YouTube, the survey asked the students to describe briefly what they believed were the benefits of listening to or watching more than one performance of a specific work. The students' responses revealed a range of foci that covered both aural and visual aspects of music performance. Interpretative decisions, and the ability to gain ideas to incorporate into individual practice, were by far, the most common areas of interest. As one student commented: Well obviously it gives you a different interpretation. There isn't usually one 'correct' interpretation of a piece so it is beneficial to see a few different versions. Gives you ideas for how you could interpret it (student respondent \#6).
Another student's feedback provided some insight as to the type of ideas found through listening to more than one performance: It's all about interpretation, maybe somebody has a new take or outlook on the same piece that transforms the original. It helps feed my mind with more variables or different emotional moods that you never would [have] thought possible from the original written work (student respondent \#7).

Still other students shared their awareness of the impact listening to other performances had on their individual practice. As one student wrote, "by watching different versions you are less restricted and more likely to discover your own way of performing the piece of music" (student respondent \#39), a comment echoed by another student who wrote, "Hearing more versions of a piece of music provides a greater understanding of the possibilities for your own (student respondent \#20), and a third commented:

I find it beneficial to see how different performers have interpreted and executed the same work. I often make a point of listening to performances by males and females. Females are generally physically smaller and not as strong as males, and I find it beneficial for my own performance practice to see how they deal with particular aspects of works (student respondent \#35).

A number of students also reported that they undertook aural analysis and/or engaged in reflective thinking after watching performances on YouTube. For some students the reasons were to absorb the details of a specific performance, as was indicated by one student who wrote that he/she liked to "transcribe melodic ideas or chord substitutions from improvised sections or the head that I find interesting" (student respondent \#9), and another who pointed out that "in some cases, such as big band arrangements, it helps to do a quick analysis of the piece for reference and ideas" (student respondent \#6), while a third stated "I do try and reflect upon the differences of each interpretation and compare them to each other and describe what I enjoyed about each performance" (student respondent \#2). Another student indicated reflection helped to identify physical and technical aspects of the performance: "I reflect on the visual aspects like stage set up, body movements, breathing, the persona given, and aural aspects like articulations, different phrasings etc.."(student respondent \#1), while for another, analysis formed part of a process of modelling "I often transcribe, sing and play artists 'versions"' (student respondent \#11).

The survey also asked the students their opinion as to the importance of watching a performance. The students' responses indicated that technical issues were by far the most important reason for the desire to watch music performances. Many of the students' comments that indicated the importance of technical 
issues included commentary on both instrumental techniques and stylistic issues. For example one student wrote: "I look for breathing, styles in which they play it too. Pretty much all aspects of the performance" (student respondent \#4) while another commented: I watch for their technique and interaction with other instrumentalists if there are others. If it is an orchestra, I watch the conductor as well as the players. I like to see the visual part as well as hearing the music- it helps to see how a certain dynamic, accent or 'mood' is conveyed, the 'gesture' of it (student respondent \#15). Students also noted the variety of footage available: Recently I have been watching clips of performers who use unorthodox techniques to produce sounds on the electric guitar. These sounds can be illusive [sic] without actually seeing it. YouTube not only allows me to see how these sounds are produced but often has footage of the performers talking about it (student respondent \#30).

Some students also indicated the importance of engagement and stagecraft. One student commented he/she looked particularly at "how the performer engages with the music and conveys the music to the audience" (student respondent \#11), and another wrote "I like seeing how they move to the music, use their bodies, interact with the audience and conductor, and whether they have an expressive face or not (student respondent \#23). Many comments indicated that engagement encapsulated both stage presence and technical aspects of music making. As one student wrote "You can learn stage presence, for violin especially the bowing techniques and fingering. Watching the performer really teaches you a lot" (student respondent \#13), and a second student expressed similar ideas: When watching a performer I like seeing the way they feel the music, the way they move to what they're playing, the expressions on their face, the dynamics in a song, accents, where they put all those things. To be able to see a piece through someone else's eyes (student respondent \#22). Interestingly the commentary was fairly evenly divided: for every comment praising the usefulness of watching music performance, there was an opposite one indicating that the visual aspect was of little importance. Indeed for one student "Technique would be the only constructive reason to watch" (student respondent \#5), but another reflected "I think I find it more interesting than important" (student respondent \#21) and for another context was a determining factor: [It] depends on what I'm listening to. For violin concertos or instrument specific performances, yes, it is helpful and more engaging to watch them play. For pop songs or compositions I am listening to, less important if at all... w watch the performer to see their stage presence, their flair, commitment to the performance, the way their body moves and is affected by the music. I guess I notice their technique as well but don't usually scrutinise it (student respondent \# 6).

\section{Conclusions}

The 2012 YouTube, You Learn pilot study confirmed that, for music performance students, access to visual and aural resources greatly aided the understanding of performance practice issues. The assignments from the pilot study required the students to analyse video footage of two performances and then engage in class discussions about each presentation, which resulted in an enhanced understanding and shared awareness of historical and current performance practices. Additionally, and perhaps even more importantly, it was through the task of comparing two performances of the same piece of music, that the students were able to develop the vocabulary necessary to discuss performance practice issues objectively and effectively.

The results of the 2014 follow up study strongly suggests that the students' earlier exposure to YouTube as a teaching tool in the curriculum has been beneficial: the development of critical awareness and judgement in that forum would appear to have contributed to this cohort being willing to engage extensively with this audio-visual resource as a tool for personal learning. When asked to describe their most recent, helpful use of YouTube the students' responses revealed an array of interests that were informed through YouTube engagement. One student, for example, wrote, "I watched a number of reed making videos, to see the various techniques and their outcomes" (student respondent \#20), and a second commented: I was attempting to compose a piece with both Middle Eastern and Celtic influences. YouTube allowed me to access many recorded examples of these styles of music so that I could analyse the music and gather ideas to inform my compositional process (student respondent \#9). Modelling from performance teachers and iconic performers has historically played a major role in the development of music performance students, even at the advanced level [1]. The feedback from students from the students highlighted the potential YouTube has to inspire students, and facilitate such modelling, as is evident in the following comment "watching Nikki Yanofski performing 'I got rhythm' her vocal 'scat' and unison solo with guitar and piano is something I would like to attempt" (student respondent \#18). Strong appreciation of the resource was also evident in many responses to the survey questions. One comment in particular, reflected on the range of materials available on YouTube:

It's fantastic to be able to pull up interviews, live footage, studio sessions etc. it's a great resource. No doubt if you wanted to know about 'Martian nose flute' then there's probably not much waiting for you 
on YouTube or online, but seriously, almost anything sensible you could want to research you know you will find it somewhere online (student respondent \#7). As foretold in The Horizon Report of 2011, and confirmed in 2015, some comments by the students emphasised the influence of the ease afforded by using personal devices to access learning resources: "I have a smart phone so I can watch whatever I want, when I want on my phone" (student respondent \#22), but another comment was an important reminder not to assume that all students had equal access to technology. As one student described it, "I don't have the internet at home, but if I could, I would watch lessons and masterclasses regularly. It is a great resource" (student respondent \#24). The comment highlights one of the challenges, noted in the 2015 Horizon Report that had the potential to impede technology adoption in higher education: "discussions ...have raised concerns regarding a digital divide - some pundits caution that BYOD could alienate students who cannot afford the latest technologies" [4]. The findings of this study also confirmed previous research that suggested YouTube be used in the performing arts for "knowledge generation through observation and social interactions"[6]. The students' responses demonstrated a high degree of critical judgment in both their viewing and use of online resources, but also ability and willingness to debate performance issues. One student confirmed, "I quite often participate in group discussions in person or on online forums" (student respondent \# 14), and a second student stated "sometimes I talk with other students about the performance. Usually I discuss performances with my Mum" (student respondent \#24). Online social media, most frequently Facebook and Vimeo, were also popular with the students as avenues to share resources: "If I like a YouTube video I will send the link to friends via Facebook to share it with them" (student respondent \#1) and a second demonstrated ease with a variety of social media platforms, "I upload my original material to Bandcamp, Facebook and my own personal website" (student respondent \#9). With the burgeoning amount of information and resources available to students via the internet, the teaching of methods to enhance students' abilities to evaluate quality, reliability and authenticity is an increasingly important and fraught task. The development of these skills confers important benefits for students in the performing arts, consequently teaching advantageous use of online technologies will continue to be a necessary component in curriculum design. Building into the curriculum direct comparison of online performances has been supported by this study as an effective tool for building students' critical acuity and developing the language paradigms to communicate objectively about issues of performance practice.

\section{References}

[1] DeWitt, D., Alias, N., Siraj, S., Yaakub, M., Ayob, J. and Ishak, R. (2013). The potential of YouTube for teaching and learning in the performing arts, Procedia Social and Behavioral Sciences Vol, 103, 26 November 2013, pp.1118-1126.http://www.sciencedirect.com/ science/article/pii/S1877042813038846 (Jan 30, 2015).

[2] Dickey, M. The 22 Key Turning Points in the History of YouTube, Business Insider Australia, Feb 15, 2013. http://www.businessinsider.com.au/?s=April+15\%2C+201 3+You+Tube (March 27, 2015).

[3] Johnson, L, R. Smith, H. Willis, A. Levine, and K.Haywood. (2011). The 2011 Horizon Report. Austin, Texas:The New Media Consortium. http://www.nmc.org/pdf/2011-

Horizon-Report.pdf (May 26, 2012).

[4] Johnson, L., Adams Becker, S., Estrada, V., and Freeman,A. (2015). NMC Horizon Report: 2015 Higher Education Edition. Austin, Texas: The New Media Consortium. http://www.nmc.org/publication/ nmc-horizon-report-2015-higher-education-edition/ (May 12, 2015).

[5] Jones, T. \& Cuthrell, K. (2011) YouTube: Educational Potentials and Pitfalls, Computers in the Schools:Interdisciplinary Journal of Practice, Theory, and Applied Research, 28:1, pp.75-85, DOI:10.1080/ 07380569.2011.553149 (March 19, 2015).

[6] Jørgensen, H. (2000). Student learning in higher instrumental education: who is responsible? British Journal of Music Education, 17, pp. 67-77 (March 23, 2012).

[7] Ruthmann, S. and Hebert, D. (2012). Music Learning and New Media in Virtual and Online Environments, The Oxford Handbook of Music Education, Volume 2, ed. G. E.

McPherson \& G. F. Welch. New York: Oxford University Press. pp. 567-583.

[8] Snelson, C. (2011). YouTube across the disciplines: A review of the literature. MERLOT Journal of Online Learning and Teaching. Vol. 7, No. 1, March 2011. http://scholarworks.boisestate.edu/cgi/viewcontent.cgi?arti cle $=1010 \&$ context=edtech_facpubs (March 18, 2015). Pp.159-169. 